\title{
Fraser syndrome
}

INSERM

\section{Source}

INSERM. (1999). Orphanet: an online rare disease and orphan drug data base. Fraser

syndrome. ORPHA:2052

Fraser syndrome is a rare clinical entity including as main characteristics cryptophthalmos and syndactyly. 